\title{
Australia's welfare wars: The players, the politics and the ideologies
}

\author{
Philip Mendes (3rd ed.) 2017 \\ UNSW Press, Sydney, NSW \\ ISBN 978-174223-4786, pp. 416, paperback, NZD64.99
}

$\mathrm{T}$ The second half of the title provides some very transparent clues to the ways in which Mendes goes about his work of reviewing developments and changes in Australia's welfare state over the last three decades; decades which have seen the strengthening of neoliberal and managerial frameworks throughout Australia and much of the developed (and indeed developing) world. The back cover and pp. vii-viii provide six core questions which are the basis of the book. Paraphrased, these questions are about: the failure of government policies to address structural issues of poverty and unemployment; the impact of economic globalisation on welfare state thinking; the convergence of political views among the major political parties (with the exception of the Greens); the influences of lobbying and interest groups; the reasons for the rise of poverty and inequality and the lack of concern about this issue on the part of politicians; and why do governments fail to consult with users and communities on welfare issues.

The brief for this extended review was to use the review to reflect on experiences in Aotearoa New Zealand in the light of Mendes' discussion about Australia. I will do that shortly, but the review needs to begin with a brief outline of the book's coverage. I make no claims to being an expert on the details of the development of Australia's welfare state over the time period here. Suffice to say, Mendes chronicles key aspects of this clearly and concisely, with appropriate attention to the details around the specific changes. The three sections of the book cover the context of the Australian welfare state (including discussions on neoliberalism and on globalisation and their impact on welfare state changes), the Australian political parties and the welfare state and interest groups (including ACOSS, various contributors to the debate and a brief discussion on the role of faith communities).

Throughout the book, there is a thorough and thoughtful mixture of analysis, commentary and reflection, drawing on both evidence and data from a diverse range of sources and on a solid understanding of the literature and research on the politics of welfare change. The writing style is lucid and the flow of the discussion and debate is clear and easy to follow. In short, the book is an interesting, informative and thought-provoking read. The author's social democratic and participatory approach is clear throughout (and quite explicit) but does not "get in the road" in the discussion.

What a pity there is no comparable volume for this country because my intuitive sense is that the analysis would follow similar lines, with one notable difference, which I will return to below. On many, many occasions I found myself reading a sentence or paragraph and substituting the relevant Aotearoa New Zealand institution and reflecting that the sentence or paragraph would hold equally well for this country. The four examples below will illustrate; it would have been possible to provide a number of others.

- Australian government policies are based on motivating and disciplining welfare recipients and reintegrating 
them with mainstream social values and morality (p. 9).

- Neoliberal ideas of small government, free markets and limited social expenditure have provided the ideological inspiration for cuts to the welfare state (p. 17).

- Work was assumed (by the social security review) to provide major health, social and economic benefits for both the individual and the wider community. There was little reference to addressing the financial needs of long-term income security recipients (pp. 42-43).

- Probably the strongest factor contributing to retrenchment is the domination of individualistic values and beliefs. Poverty and disadvantage are increasingly constructed as matters of private individual choice and behaviour rather than as collective moral and social responsibilities (p. 332).

A central part of his thesis is that the welfare state needs to be sustained, albeit with some important differences from its historical form. It "represents a significant gain for poor and working class people in the struggle for a fair distribution of wealth and income" (p. 5). The neoliberal revolution is, he argues, a reversion to the 19th century. Neoliberal values have won the day because the rich and powerful have more resources, have engaged effectively with global interests and have used a set of strategies and articulated ideas and proposals which have been taken up by the media while much of the Left has been undecided about its approach to the welfare state. Importantly, the media have close connections with powerful economic interests and, in some instances, are owned by them. Does this not sound very like Aotearoa New Zealand ?:

"Typically, they [think tanks] publish simplistic but innovative and accessible arguments in non-refereed pseudo-academic journals which are then easily reshaped as opinion pieces in daily newspapers or repeated by sympathetic newspaper columnists or talkback radio hosts" (p. 86).
Turning to the local comparison, I noted above that there is one important difference which an equivalent Aotearoa New Zealand study would need to attend to, namely the contribution of Māori and the role of Te Tiriti in shaping various aspects of the reforms on this side of the Tasman. In various places Mendes notes the significance of the changes for Aboriginal and Torres Strait peoples (see, for example, pp. 236 et seq.). Those changes are clearly significant and, equally, it is significant that Aboriginal and Torres Strait peoples had no meaningful role in shaping or influencing those changes.

A comparable review here would need to examine the role of a diverse range of tangata whenua interests in shaping various dimensions of the Aotearoa New Zealand changes, in some instances with some important impacts and, in others, with little or no impact. Moreover, it would be inappropriate to assume that there is a simple totality about those interests-the different interests will be as important as the common interest. Any discussion of the role of tangata whenua would need to explore both activist and academic contributions to the changes and the challenges to those changes. Significantly, a review would note that Māori have borne the brunt of the effects with very high poverty and unemployment rates and higher rates among the homeless, for example.

\section{A brief Aotearoa New Zealand story}

While it is not possible in the context of this review to undertake a comparable analysis of the Aotearoa New Zealand experiences, it is possible to indicate some of the issues which such a review might explore and some of the information we currently have. We know, for example, that poverty (especially child poverty) and inequality have increased significantly over the last three decades. We know too, that housing access, affordability and quality are much more difficult and that public provision has declined significantly, particularly in relation to access to state housing. We also know that there have been 
significant changes to social security (now known as income support). Rates have been cut (and never restored), there has been a significant shift from rights to responsibilities and a fundamental change in the framework for social security with paid work being the dominant motif. Moreover, the approach has become more punitive, with recipients being subject to a range of requirements as to their behaviour and sanctions surrounding noncompliance with those requirements. In a broad sense, many of the directional changes which Mendes identifies in the directions of Australia's welfare provision, coverage and access and the attendant neoliberal framing are echoed very loudly in this country.

In the light of the current focus and debate in this country, it is timely to note Mendes' references in chapter four to the idea of social investment as a basis for reshaping and redeveloping the welfare state. It is not, however, the neoliberal and conservative social investment as we know that term in this country, far from it. "Social investment", he notes, "refers to productive future-oriented forms of social spending that promote inclusion of all citizens in the social and economic mainstream rather than merely repair the short-term damage experienced by groups suffering disadvantage" (p. 119). That, he argues, has to be accompanied by a much more participatory reformed welfare state "based on a genuine partnership between the state, welfare consumers and the community" (p. 4). This is the very antithesis of the welfare state changes in this country and of the approach adopted to social investment here. Mendes talks of the approach of one of the right-wing critics to child protection-social work practice should, the critic argues, "return to ... prompt and permanent removal of abused and neglected children from their parents" (p. 82). Does this not sound scarily like the vulnerable children approach to social investment?

One of the significant areas of focus in Australia's Welfare Wars is Mendes' discussion of the role of right-wing think tanks, right-wing political interests and key personnel in shaping the new directions and guiding the war effort. Here too, there are very interesting and significant parallels in New Zealand's experiences. The work of the Business Roundtable (and its current reincarnation in the New Zealand Initiative) and associated economic and political interests, influences and related think tanks is an obvious starting point for examination as they have pursued their agenda of economic and political liberalisation. As in Australia, there have been other voices such as those concerned with child poverty, the trade union movement, some social service practitioners and leaders and a small number of academics (Jane Kelsey is a good example) whose work and activities have been based around (and produced challenges to) "the new normal." However, as in Mendes' examination of the Australian experiences, even a cursory review indicates that the Aotearoa New Zealand changes have been dominated by neoliberal economic and political interests, to the detriment of the poor and powerless.

In more recent times, the role of key individuals such as Paula Rebstock in both the social security reforms and the changes to care and protection of children (through the Expert Panel) would provide a very interesting investigation, especially when placed alongside her background with the Commerce Commission and her current role as Chair of the Accident Compensation Corporation Board. As in the Australian story, alternative views and directions have been systematically ignored and/ or sidelined. The work of the Alternative Welfare Working Group and Child Youth and Family's Workload and Casework review provide good examples. The role of other key figures (including, but not limited to, ministers of the Crown) in the welfare changes of the 1990s and subsequently and the more recent raft of changes would be an important part of the New Zealand story.

In his examination of "contributors to the debate" (ch. 9), Mendes has an interesting 
discussion on the contribution of social workers and social work associations. While noting the ethical basis of policy action as a legitimate core part of social work practice, Mendes goes on to observe that AASW seems: "to have had only minimal impact on policy debates" (p. 270). This he attributes to lack of adequate preparation in education programmes for undertaking such action, the role of public sector employment in limiting opportunities for speaking out, the lack of social work leadership profile in the media and in the wider public and uncertainty among AASW as to who it represents. Might these factors also be significant in Aotearoa? The two case studies he uses to discuss the influence of social work lead him to note that: "narrower professional social work identity and broader social justice advocacy concerns can be reconciled and synthesised to good effect in social action campaigns" (p. 275). This is an important rejoinder for social workers in Aotearoa as we engage and struggle with a range of changes in health and social services in areas such as the care and protection of children, provision of mental health services and services for people with disabilities—-to name but three examples. The interesting question is how we respond to that challenge-what kind of social work/social worker will we be, and become?

The ultimate question in any book review is: does this work warrant reading? The answer here is an unreserved "yes" — and reflect on the issues and questions for understanding welfare changes in your country as you do so.

Reviewed by Mike O'Brien University of Auckland 